\title{
Psychosocial Correlates of Job Stress among Lecturers of Tertiary Institutions in Rivers State
}

\author{
Manuel, Amininye Macgregor (PhD)*, Essien, Bassey Samuel \\ Department of Educational Psychology, Guidance and Counselling University of Port Harcourt, Nigeria \\ *Corresponding Author: Manuel, Amininye Macgregor, Department of Educational Psychology, \\ Guidance and Counselling University of Port Harcourt, Nigeria
}

\begin{abstract}
This study investigated psychosocial correlates of job stress among lecturers of tertiary institutions in Rivers State. The purpose of the study was to determine the extent to which work condition, self-concept and gender contribute to job stress among lecturers in tertiary institutions. A sample of 397 lecturers were selected from three tertiary institutions in Rivers State. The instrument used for the data collection was a questionnaire named Correlates of Job Stress Questionnaire (CJSQ) and the Job Stress Inventory (JSI). The study used simple regressions, mean and standard deviation and analysis of variance (ANOVA) associated the regression to analyze the data. The result shows that work condition $(p=0.006<-0.05)$ has significant relationship with job stress while self-concept $(p=0.221>-0.05)$ had no significant relationship with job stress. On the other hand, although female lecturers showed slightly higher response to job stress than their male counterparts it was not significant $(p=0.161>-0.05)$. Based on the findings, some recommendations were made to the Government, other employers of lectures and lecturers themselves which if implemented would bring about reduced stress to lecturers to lectures of tertiary institutions.
\end{abstract}

Keywords: Psychosocial, job stress, self-concept, work condition and gender

\section{INTRODUCTION}

At one time or the other, individuals pass through stressful situations which maybe as a result of transition of college, forming new relationships, going for lectures or trying to meet up with a deadline. Stress is described as the process whereby an individual responds to an event that is challenging or threatening. Although a measure of stress is good since it injects energy and motivates one to excel but generally, stress is uncomfortable and unhealthy because what stress the "mind" also affects the body (McEwen, 1998). As an individual previously the researcher thought that stress only affected top businessmen and women who shuttle different states and countries while engaging in their business activities including politicians, who experience sleepless nights while trying to govern the populace but it is a known fact that no living creature is free from stress regardless of the person's age, gender, qualification, tribe or nationality since all of us facedifferent challenges from time to time as a result of losses, changes and conflicts.

Lazarus in Meyers (2009) stated that stress arises less from the event itself than from how we appraise it. This suggests that if one sees an event as a welcome challenge such a person will be focused and motivated to overcome and excel in the event, for example writing an examination, if the event is seen as a challenge that will make one excel it will not be stressful. On the other hand, if it is seen as a threat, it will lead to negative reactions which in turn breed distress which can affect our physical health. Stress is also seen as a negative emotional and physiological process that occurs as individuals try to adjust to or deal with stressors, which are environmental circumstances that disrupt, or threaten to disrupt individuals' daily functioning and cause people to make adjustment (Taylor, 2009). It is a phenomenon that affects all.

Specifically, job stress is defined as the harmful physical and emotional responses that occurs when the requirement of the job do not match the capabilities resources, or needs of the worker. The National Institute for Occupational Safety and Health (NIOSH, 2014) education and information division sees job stress as any reaction whether physical or emotional that a worker will exhibit due to the fact that what is requires from his job does not equate with his capabilities and resources. It is also 
seen as the reaction workers may have because they are confronted with work demand and pressures that does not match with their knowledge and abilities (WHO, 2017). Although no work place is free from pressure due to demands of the work environment, but if an individual perceived these pressure as being okay, he will be motivated to work hard and stay alert but in a situation whereby this pressure became overwhelming or unmanageable it leads to stress which can affect the worker's health negatively and his job performance. From this, it can be seen that job stress in unavoidable and inescapable in life and since it is impossible to eliminate stress. It is imperative to cope with it so as to reduce the negative effect. Stress is known to affect everyone irrespective of their socio-economic background; therefore workers are not left out. However, there are other factors that may affect job stress, these include self-concept.

Self-concept is defined by Merriam-Webster dictionary to be the mental image one has of oneself. It is the collection of beliefs about one's own nature,unique qualities and typical behaviour (Weiten, 2004). The way an individual view himself or herself mentally and what he thinks and feels about himself is self-concept. Self-concept is subjective in nature in the sense that it may not be entirely consistent with an individual's experience. One can distort his experiences so as to promote a relatively favourable self-concept. In the same vein, Myers (2009) sees self-concept as all the thoughts and feelings we have in response to the question "who am I", he went further to explain that if we fall short of our ideal self we will be dissatisfied and unhappy, on the other hand if we have a positive self-concept and think highly of ourselves we act and perceive the world positively. It can also be said to be the collection of beliefs we have about ourselves which includes elements like racial identity, academic performance, sexual identity and gender identity. From these definitions, it can be deduced that the way an individual perceive, evaluate or thinks about himself is self -concept and this may either increase or reduce his job stress. Rad and Nasir (2010) studied burn out and career self concept among teachers in Mashhad, Iran. Data was collected using the Maslach Burnout Inventory (MBI, Maslach\& Jackson, 1981, 1986) but was modified to 22 items while for the statistical analysis, t-test and Pearson correlation coefficient were used. In burnout and career self-concept between male and female teachers, the result shows a negative correlation between self -concept and burnout. On the other hand, Nwafor, Immanuel and Nwosu (2015) carried out a study on the role of nurses' general self-concept on the relation between job satisfaction and burnout using 170 nurses in two Nigeria public health facilities. The findings show that nurses general self-concept correlated positively with job satisfaction but both self-concept and job satisfaction correlated negatively with burnout. Further analysis with conditional process analysis shows that nurses' general self-concept mediated the relationship between job satisfaction and emotional exhaustion, job satisfaction and reduced personal accomplishment but did not mediate the relationship between job satisfaction and depersonalization while the previous study focused on the role of nurses' general self-concept on the relationship between job satisfaction and burnout, this study will focus on lecturers and the psychosocial correlates of job stress.

\subsection{Another Factor that Could Influence Job Stress is One's Work Condition.}

Work condition has to do with all the issues involved in a person's job like remuneration, hours of work, physical condition of place of work, rest periods, mental demands of the job and the work schedules that exist in any work place (International Labour Organization, 2017). From this definition, it can be seen that how much an individual receive at the end of the month as salary is included in the work condition implying that if the salary is large in terms of remuneration, the work condition is good. If the hours spent in one's work place is flexible and not too much shows that the work condition is good, the physical conditions of the work place includes well ventilated work space, suitable and natural lighting, clean environment, maintenance of the workplace, electrical equipment, nice temperature inside the offices during work hours, toilets should be readily accessible and very clean, good portable water for drinking and washing (Unison National, 2017). The condition of one's place of work also includes the number of weeks the person can go on leave, if the work will include access to training, flexible working arrangements and performance reviews. The environment in which one works and which is influenced by factors like amenities, cleanliness, equipment, and lighting and overtime paid are all included in work conditions. According to the International Labour Organization (ILO) (2018), it stated that condition of work includes the hours of work, rest periods and work schedule, remuneration and the physical and mental demands that exist in the work place. Rizwan\&Jamil (2014) studied the impact of the job stress, job autonomy and working conditions on 
employee satisfaction in Punyab (Bahawakpur) Pakistan. The population used workers in the industries and private banking financial institutions and the sample size was 160 from the administrative, accounts and finance departments. Descriptive research was used and finance departments. Descriptive research was used and the instrument: employee satisfaction, job autonomy and working conditions were used to collect data. Regression analysis techniques was used to analyze the data collected. The result shows that job stress has a relation with employee satisfaction, job autonomy and working conditions also has positive impact on employee satisfaction.

Gender could be another factor that may influence job stress. The psychological experience of one's sex is gender. (Gentile, 1993). All the characteristics both biological and socially in which people or the society at large defines as male and female is gender. It can be divided into two aspects which are gender identity which included our personalities, a major component of our self-concept and our subjection experiences of being a male or a female while gender role involves all the behaviours that tell others nonverbally the degree to which we are either masculine or feminine. These behaviours are basically defined by our culture. (Money, 1987,1988) in Lahey (2009). There is difference in both genders when it comes to physical strength and skills. It is observed that men have greater upper-body strength than women while it is only women that can be pregnant, give birth and breastfeed infants. When it comes to the differences in cognitive ability and achievement, overall women and men are more similar in terms of cognitive ability and academic achievement but there are some specific areas, in which men excel more than women and some in which women excel more than men. In the area of mathematics, science and social studies, men do better than women while women performed better than men in areas like language skills, verbal memory, perceptual speed and fine motor skills (Halpern, 2004; Stumpf and Standle, 1998) in Lahey (2009). In the area of emotion and social behavior, many studies carried out on these areas suggested that women are able to conceal their emotions, are open, cooperative, nurturing, trusting, helpful and friendly more than men. On the other hand, men are dominant, competitive and assertive than women (Eagly, Dickman, Johannesen-Schidt 7 Koeniy, 2004).

Sofoluwe, Akinsolu and Ogbudinkpa(2015) studied the relationship between genders, stress and job performance among academic staff in tertiary institution in Anambra state. The research design was descriptive survey of correlational type while stratified random technique was used to select a total of 500 participants out of the 1200 target population from the four tertiary institutions in Anambra state. The instruments used for the study were Gender Stress Questionnaire(GSQ), Academic staff Job Performance Questionnaire(ASJPQ), Academic Staff Stress Management Check list(ASSMCL) and Academic Staff Publication Performance(ASSP). The data was analyzed using multiple regression and pearson product moment correlation coefficient statistics. Findings revealed that gender and stress significantly influenced academic staff job performance in tertiary institutions in Anambra state. It further shows that male lecturers had more publications than female lecturers and that a significant relationship exists between gender and stress.

Also miller, Greyling, Cooper, Lu Sparks and Spectar(2000) studied occupational stress and gender and culture in other to examine the interaction of gender and culture in manager's experiences of work stress. The study was carried out in four countries South Africa, United Kingdom, United States of America and Taiwan. The instrument used to collect the data was from collaborative international study of managerial stress (CISMS) from four countries while the sample size was 822 managers from the four countries. The data was analyze using ANOVA and t-test and the findings shows that there were no differences in the stressors experienced by men and women in the four countries apart from organizational climate but when it comes to strains experienced by men and women in terms of mental and physical well-being, men exhibited better mental and physical wellbeing than women.

\section{Statement of the Problem}

Lecturers are saddled with the responsibilities of educating students in tertiary institutions and in other to carry out these responsibilities effectively, they have to lecture the students whenever it is their period of lecture time, give assessment test, set examination questions, administer these examination, mark and grade the papers they are also expected to carry the research work at their spare time in other to publish. In addition to these most of them are fathers and mothers who also have to care for their various family obligations and responsibilities. 
In a bid to handle all these responsibilities they may not always attend classes to lecture the students when they are supposed to do so. Some in the rare occasions that they attend classes do not lecture the students to their understanding rather they spend the time telling stories that are not relevant to their course. Added to these, some lecturers lecture for one hour some do not also keep to the specific time allotted to them on the time table. Lecturers also supervise students that are writing their projects and make corrections or suggestions where necessary, sad to say some lecturers may not do these as at when due because of their tight schedule which may slow down the student also when some students come for corrections some lecturers do not keep to the appointments made with the student repeatedly because of other engagements. Students often come to school to see their supervisors as arranged only to find out that they are not in school and will not be in school throughout that day and some of these students are not residing in Rivers State. Therefore the researcher will examine if these could be connected to job stress among lecturers of the University of Port Harcourt, Rivers State University and Ignatius Ajure University of Education in Rivers State.

Aims and Objectives of the study

The aim of this study was to investigate the psycho-social correlates of job stress among lecturers of tertiary institution in Rivers State. Specifically the objectives of this study was to:

1. Investigate the extent self-concept relates to job stress among lecturers in tertiary institutions in Rivers State.

2. Find out the extent work condition relates to job stress among lecturers in tertiary institutions in Rivers State.

3. Determine the extent gender influences job stress among lecturers in tertiary institutions in Rivers State.

\subsection{Research Questions}

The following research questions were developed to obtain results for the study:

1. To what extent does self-concept relate to job stress among lecturers in tertiary institution in Rivers State

2. To what extent does work condition relate to job stress among lecturers in tertiary institutions in Rivers State

3. To what extent does gander influences job stress among lecturers in tertiary institutions in Rivers State

\subsection{Hypothesis}

The following null hypotheses were postulated to guide this study

1. There is no significant relationship between self-concept and job stress among lecturers of tertiary institutions in Rivers State.

2. There is no significant relationship between work condition and job stress among lecturers of tertiary institutions in Rivers State.

3. There is no significant difference in job stress of male and female lecturers of tertiary institutions in Rivers State

\section{RESEARCH METHODOLOGY}

The research design for this study is correlational design and ex-post faction which has to do with finding out the extent of relationship between two or more variables. It correlational because the researcher attempt to find out the relationship between the dependent variable job stress and the independent variables like self-concept and work condition also Ex-post fact design is used to ascertain the influence of gender on job stress. The population of the study consists of lecturers in three tertiary institutions in Rivers State which are 2448. The population for the University of Port Harcourt was 1,433 lecturers (ASUU secretariat), Rivers State University 576 (office of the Registrar), Ignatius Ajuru University of Education 439 (office of the registrar). A sample of four hundred and two lecturers was selected for the study applying the Taro Yemen, formula while the non-proportionate sampling technique was used to select 134 lecturers from each of the three major 
Universities in the state. Two self- developed instruments named the correlates of job stress questionnaire (CLSCE) and the job stress inventory (JS1) was used for the data collection. The CJSCE is a 4 point likert scale that contains two section (A\&B) section A contains gender information instruction on how to respond to the instrument while section B contains 2 sub sections that contains items designed to elicit responses from the respondents on self-concept and work condition, the 4 point likert scales strongly agreed, agreed, disagreed and strongly disagreed (AS, A, D, SD) carries weight 4,3,2 and 1 for positively keyed items and a reverse for negatively keyed items on the other hand the Js1 is also designed in a 4- point likert of strongly Agreed, Agreed, disagreed and strongly disagreed. It contains twenty items designed to range the stress level of the respondents. It also carries the weight 4,3,2 and 1 for positive items and vice-versa for the negative items. The validity of both instruments were determined by giving copies to three experts in measurement and evaluation they offered suggestions, corrections and modifications which were implemented. The reliabilities of the both CJSCE and Js1 were determined using Cronbachalpha. Thirty copies of the instrument were given to 30 lecturers who are not part of the targeted sample but with similar job description characteristics. After their response, the researcher subjected their scores to Cronbachvia SPSS. A reliability index of 0.87 was realized for CJSCE and 0.84 was realized for JS1.

The researcher administered the instrument directly to the respondents with the help of a research assistant who has been trained by the researcher. Simple regression was used to answer research questions 1-2 while mean and standard deviation was used to answer research question 3. Analysis of variance (ANOVA) associated with the regression was used to test hypotheses 1 and 2 while t-test was used to test hypotheses 3 at 0.05 alpha level

\subsection{Results}

Analysis of data in this study was done in line with the research questions and hypotheses:

Research Question One: To what extent does self-concept relate to job stress among lecturers in tertiary institution in Rivers State?

Hypothesis One: There is no significant relationship between self-concept and job stress among lecturers in tertiary institution in Rivers State.

Table1. Simple linear regression between self-concept and job stress among lecturers in tertiary institution in Rivers State.

\begin{tabular}{|c|c|c|c|c|c|c|}
\hline $\begin{array}{l}\mathrm{R} \\
0.06\end{array}$ & & $\begin{array}{l}\text { R Adj } \\
0.004\end{array}$ & \multicolumn{2}{|r|}{$\begin{array}{l}\mathrm{R}^{2} \\
0.001\end{array}$} & $\begin{array}{l}\text { Std Error } \\
6.486\end{array}$ & \\
\hline & Sum of sq & d.f & Anova mean sq & \begin{tabular}{|l|l}
$\mathrm{F}$ & $\mathrm{a}$ \\
\end{tabular} & Sig. & Result \\
\hline Regression & 63.163 & 1 & 63.163 & & & \\
\hline Residual & 16617.592 & 395 & 42.070 & 1.5010 .05 & 0.221 & $\begin{array}{l}\text { Insignificant } \\
\text { (Accepted Ho }\end{array}$ \\
\hline Total & 16680.756 & 396 & & & & \\
\hline
\end{tabular}

Table 1 shows that $R=0.062, R^{2}=0.004$, adjusted $R^{2}=0.001$ while standard error $=6.486$.

From the $\mathrm{R}^{2}$ values, it is seen that self-concept relate only $0.4 \%$ with job stress among lecturers in tertiary institutions. The associated ANOVA also reveals calculated $\mathrm{F}=1.501$ while sig value $=0.221$. Hence, since sig value

$(\mathrm{F}=0.221>0.05)$ is greater than 0.05 , the hypothesis is accepted meaning that self-concept does not have any significant relationship with job stress among lecturers in tertiary institution in Rivers State.

Research question 2: To what extent does work condition related with job stress among lecturers in tertiary institution in Rivers State?

Hypothesis 2: There is no significant relationship between work condition and job stress among lecturers

Table2. Simple linear regression analysis of relationship between work condition and job stress among lecturers in tertiary institutions in Rivers state.

\begin{tabular}{|c|c|c|c|c|c|c|}
\hline \begin{tabular}{|l}
$R$ \\
0.137
\end{tabular} & & $\begin{array}{l}\text { R Adj } \\
0.019\end{array}$ & & $\begin{array}{l}\mathrm{R}^{2} \\
0.016\end{array}$ & $\begin{array}{l}\text { Std Error } \\
6.437\end{array}$ & \\
\hline & Sum of sq & d.f & Anova mean sq & \begin{tabular}{|l|l}
$\mathrm{F}$ & $\mathrm{a}$
\end{tabular} & Sig. & Result \\
\hline
\end{tabular}




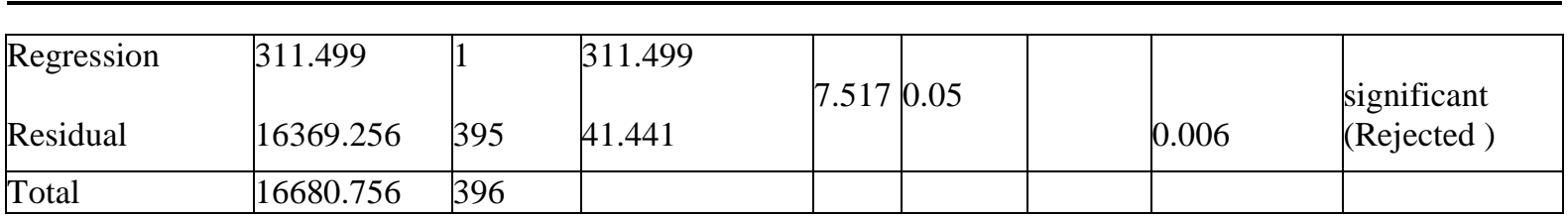

Table 2 reveals calculated $\mathrm{R}=0.137, \mathrm{R}^{2}=0.019$, adjusted $\mathrm{R}^{2}=0.016$ and standard error $=6.437$. This means as shown by the $\mathrm{R}^{2}$ value that work condition account for $1.9 \%$ of the level of job stress experienced by lecturers in tertiary institutions in Rivers State. The associated ANOVA reveals calculated $F$ value of 7.57 while a sig value of 0.006 was realized. Therefore, since the $\operatorname{sig}(p=0.006<$ 0.05 ) is less than the alpha of 0.05 , the null hypothesis is rejected meaning the work conditions certainly has a significant relationship with job stress among lecturers in tertiary institutions in Rivers state.

Research Question 3: To what extent does gender influence job stress among lecturers in tertiary institutions in Rivers State?

Hypothesis 3: There is no significant difference in Job stress of male and female lecturers in tertiary institutions in Rivers State.

Table3. Mean and standard deviation on the influence of job stress on male and female lecturers

\begin{tabular}{|l|l|l|l|l|l|l|l|l|l|}
\hline Gender & $\mathrm{N}$ & Mean & Std. Deviation & Df & t-cal & a & t-crit & Sig. & Result \\
\hline Male & 176 & 38.75 & 6.40 & -395 & -1.404 & 0.05 & 1.960 & 0.161 & Insignificant(Accepted Ho \\
\hline Female & 221 & 39.67 & 6.51 & & & & & & \\
\hline
\end{tabular}

From table 3 , it is seen that male lecturers that responded were 176 while females were 221 . Their mean and standard deviation values stood at 38.75, 6.40 and 39.67, 6.51 respectively. From their mean values, it is seen that female lecturers are being influenced by job stress more than their male counterparts or that they have higher mean score than the males. Furthermore, a calculated t of -1.404 was realized against a critical of $1.960 \mathrm{sig}$. value 0.161 hence, since sig. value $(\mathrm{P}=0.161>0.05)$ was alpha at 395 degrees of freedom. The null hypothesis is accepted meaning that actually there is no significant difference in job stress pattern between the male and female lecturers in tertiary institutions in Rivers state.

\subsection{Summary of Findings}

1. Self-concept has an insignificant relationship of about $0.4 \%$ with job stress.

2. Work condition has a significant relationship of about $1.90 \%$ with job stress.

3. Female lecturers are prone to more job stress than their male counterparts however; the mean difference of 0.92 realized does not have any significant differences in job stress.

\subsection{Discussion}

From the findings in research questions and hypothesis one, it revealed that self-concept does not have any significant relationship with job stress among lecturers in tertiary institutions. This findings means that the way individual lecturers see themselves cannot determine if they will be stressed on the job or not. The findings also imply that irrespective of how lecturers see themselves individually it cannot help in managing their stress in the work place. This may also be because all lecturers have passed through various forms of stress and are quite aware of the fact that irrespective of their perception of self. It cannot add or subtract from the extent of stress they undergo at their places of work. This finding comes as a surprise to the researcher because the researcher believed that if an individual sees himself as capable of dealing with any situation, this will help him in managing the level of stress in the work place but those who see themselves as not being able to confront their situation will not be able to manage the level of their stress. Also, irrespective of how an individual sees himself or herself stress, boredom, fatigue and other things may still have a huge impact on the job stress of the individual. The present study is in agreement with that reported by Rad and Nasir (2010).

The second finding revealed that work condition has a significant relationship with job stress of lecturers in tertiary institutions. The finding implies that the physical and mental work environment of an individual can determine if he or she will be stressed at the end of the day or not. It means that all the lecturers have agreed that poor working conditions as reflected in the conditions of the classes, 
offices and other facilities is a major factor in job performance among employees from their assertion, where the lecturers do not have good ventilation, good teaching aids, table, chairs, clean and comfortable offices, etc. their work performance will be marred and they will start to perceive their job as stressful compared to where these provisions are made. This finding also denotes that in situations where the job stress level is to be reduced, government and other concerned agencies should do more in providing better working condition. This finding is what the researcher expected because to be best of her knowledge the condition of work impacts greatly either positively or negatively on the workers (employees). The work of Rizwan and Jamil (2014) earlier reported supported the present finding when they reported a significant relationship between work condition and job stress.

Finally research finding on research question three, reveals that female lecturers are prone to job stress than the male lecturers. This may mean that men have more enduring capacity to cope with stress more than the female lecturers. The reason maybe that as wives, mothers, aunties and ground mothers, female lecturers are involved with greater domestic work than their male counterparts. It could be that before female lecturers comes to work they may have engaged in one or more form of household chores like washing, preparing breakfast, preparing their kids for school etc. which maybe exhausting thereby making it impossible for them to measure up to their male counterparts in dealing or coping with job stress. The finding also revealed that regardless of these differences in job stress coping abilities between male and female lecturers it is not significant. This finding is in line with that reported earlier by Miller, Greyling, Copper, Spark and Spectar (2010) who noted through their findings that there were no significant differences in the stressor experienced by men and women in four countries.

\section{CONCLUSiON}

In conclusion, while job stress may affect lecturers in tertiary institutions, it is possible for them to cope if their work conditions are favourable and conducive for both teaching and learning.

\section{RECOMMENDATIONS}

1. Although there is no significant relationship with job stress and self-concept, lecturers should still work on their self -concept because the researcher strongly believe that if they see themselves as having ability to cope or deal with any stressor. It will help them manage the job stress they are currently experiencing.

2. Government and other employers should ensure that the physical condition or environments which lecturers work are properly organized. They should provide spacious classroom, wellfurnished offices and well ventilated spaces to enable them carryout their work with ease.

3. Irrespective of gender, equal provision should be made for both male and female lecturers in terms of motivation.

\section{REFERENCES}

[1] CDC-NIOSH Publications and publications and products. Stress at work (99-101).

[2] Eagly, A. H., Diekman, A. B., Johannesen-Schmidt, M. C. \&Koening, A. M. (2004). Gender gaps in sociopolitical attitudes: A social psychological analysis. Journal of Personality and Social Psychology, 87, 796-816.

[3] Gentile, D. A. (1993). Just what are sex and gender anyway? A call for a new terminological standard.Psychological Science, 4, 120-126.

[4] International Labour Organization- working condition ILO www.ILO.org>global>tonics>lang-en.

[5] Lahey, B. B. (2009). Psychology: An introduction. ( $9^{\text {th }}$ d). New York: McGraw-Hill.

[6] McEwen, Bruce, S. (1998). Protective and damaging effects of stress mediators.Seminars in medicine of the Beth Israel Deaconess Medical Center. N. Engl. J. Med, 338; 171-179.pmid 9428819. DOI;10.1056/NEJM199801153380307.

[7] Miller, K.; Greyling, M. Cooper, C.; Lu, L, Sparks, K. \&Spectar, P. E. (2000). Occupational stress and gender: A cross-cultural study. Stress medicine 16:127-128. Web.ba.ntu.edutw>ivolu>occupational...

[8] Myers, D. G. (2009).Psychology in everyday life. New York: Worth publishers.

[9] Nwafor, C. E. Immanel, E. U. \&Nwosu, C. E. (2015). The role of nurses general self-concept on the relationship between job satisfaction and burnout. International Journal of Africa Nursing Sciences, 3 Sept. 2013. DOI:10.1016/J./jans.2015.08.003.

[10] Rad, A. Z. \&Nasir, R. (2010).Burnout and Career self-concept among teachers Inmashhad, Iran International conference on learner diversity 2010.School of Psychology and human development, faculty 
of social sciences and humanities, University of Kebangsaan Malaysia. Available online at www.sciencedirect.com

[11] Rizwan, M. \&Jamil, m. I. (2014). The impact of job stress job autonomy and working conditions in employee satisfaction, 4(2), 2162-3058. DOI:10.52296/ijhrsv4iz.5907.

[12] Sofoluwe, A. O, Akinsolu, A. O. \&Ogbudinkpa, I. C. (2015). The relationship between gender, stress and job performance among academic staff in tertiary institutions in Anambra State Nigeria. European Scientific Journal, December 2015 edition vol.11. No. 34 ISSN: 1857-7881 (print) e-ISSN 1857-743. https://eujournal.org>article>view.....

[13] Weitin, W. (2004).Psychology themes of variation. (6 ed) Belmont, USA; Wadsworth/Thompson Learning Inc.

[14] WHO/Stress at the workplace.www.who.int>topics>stressatwp.

Citation: Manuel, Amininye Macgregor (PhD), Essien, Bassey Samuel. "Psychosocial Correlates of Job Stress among Lecturers of Tertiary Institutions in Rivers State" International Journal of Humanities Social Sciences and Education (IJHSSE), vol 7, no. 11, 2020, pp. 13-20. doi: https://doi.org/10.20431/23490381.0711003.

Copyright: (C) 2020 Authors. This is an open-access article distributed under the terms of the Creative Commons Attribution License, which permits unrestricted use, distribution, and reproduction in any medium, provided the original author and source are credited. 